\title{
IMPLEMENTASI DASHBOARD SMART ENERGY UNTUK PENGONTROLAN RUMAH PINTAR PADA PERANGKAT BERGERAK BERBASIS INTERNET OF THINGS
}

\author{
Syaiful Ahdan"1), Erliyan Redy Susanto ${ }^{2)}$ \\ 1,2Program Studi Teknologi Informasi, Fakultas Teknik dan Ilmu Komputer, Universitas Teknokrat Indonesia \\ Jl. ZA. Pagaralam No.9-11, Labuhan Ratu, Kedaton, Bandar Lampung, Lampung, Indonesia 35132 \\ Email: ${ }^{1}$ syaifulahdan@teknokrat.ac.id, ${ }^{2}$ erliyan.redy@teknokrat.ac.id
}

\begin{abstract}
Abstract - Internet of Things (IoT) is a concept that can expand connectivity connected to global networks. This study aims to build a control device that utilizes internet network technology by connecting a device through a system on a mobile device, the contribution of this research is to build a device. smart energy that is implemented in smart home features that have been connected to sensor devices so that electronic equipment can be controlled according to the desired conditions automatically or directly through the android application. Based on the results of tests carried out on the smart energy dashboard that on the usability aspect $89 \%$, functionality $93 \%$ and reliability $77 \%$, the results on testing the final efficiency aspect on the smart energy dashboard obtained the highest CPU efficiency level at $28 \%$ and stable at $10 \%$ percentage. with a memory efficiency of $47.7 \mathrm{MB}$. The conclusion of this study is that IoT technology can make it easier to control electrical devices.
\end{abstract}

Keyword: Smart Home, Smart Building, Internet of Things

\begin{abstract}
Abstrak
Internet of Things (IoT) adalah sebuah konsep yang dapat memperluas konektivitas yang terhubung dengan jaringan global, Penelitian ini bertujuan untuk membangun perangkat kendali yang memanfaatkan teknologi jaringan internet dengan menghubungkan sebuah perangkat melalui sistem pada perangkat seluler, kontribusi pada penelitian ini adalah membangun perangkat energi pintar yang diimplementasikan pada fitur rumah pintar yang telah dihubungkan dengan perangkat sensor sehingga peralatan elektronik dapat dikontrol sesuai dengan kondisi yang diinginkan secara otomatis atau dikendalikan langsung melalui aplikasi android. Berdasarkan hasil pengujian yang dilakukan pada dashboard smart energy bahwa pada aspek usability $89 \%$, functionality $93 \%$ dan reliability $77 \%$, hasil pada pengujian aspek efficiency tahap akhir pada dashboard smart energy memperolah tingkat efesiensi CPU tertinggi pada level $28 \%$ dan stabil pada persentasi $10 \%$ dengan efesiensi memori sebesar $47.7 \mathrm{MB}$ Kesimpulan dari penelitian ini adalah bahwa teknologi IoT dapat mempermudah dalam hal pengendalian perangkat listrik.
\end{abstract}

KATA KUNCI: Smart Home, Smart Building, Internet of Things

\section{Pendahuluan}

Jumlah penduduk dan jumlah investasi diiringi dengan perkembangan teknologi dalam dunia pendidikan akan terjadi dimasa yang akan datang, tak terkecuali juga dengan kebutuhan energi listrik yang akan terus meningkat seiring dengan adanya peningkatan dan perkembangannya [1]. Salah satu kebutuhan pokok masyarakat adalah energi listrik karna memiliki arti penting dalam memajukan kesejahteraan dan mencerdaskan kehidupan bangsa dan meningkatkan perekonomian negara [2]. untuk membantu pemerintah dalam mengurangi defisit sumber ketenagalistrikan di indonesia adalah dengan cara berupaya dalam hal penghematan penggunakan energi listrik. Dengan demikian maka hal tersebut langkah awal yang dapat dilakukan oleh masyarakat [3].
Smart energy merupakan salah satu area penting pada penelitian Internet of Things (IoT), teknologi tertanam (Embeded System) dapat memungkinkan setiap koneksi dan komunikasi dapat berjalan secara efesien berbasis teknologi IoT [4]. Smart building adalah lingkungan hidup dan lingkungan kerja dengan memanfaatkan penggunaan teknologi informasi dan komunikasi untuk mengkoordinasikan berbagai aspek guna meningkatkan kenyamanan pengguna, efesiensi energi dan keamaan pengguna [5].

Pengurangan konsumsi energi dapat dilakukan dengan cara mengurangi penggunaan layanan energi yang lebih sedikit atau dapat dikatakan sebagai konservasi energi. Penghematan energi sangat penting bagi kita semua, oleh karena itu untuk mempertahankan kualitas hidup yang baik, maka kita harus menemukan cara bagaimana menggunakan energi dengan bijak [6]. Banyaknya 
penggunaan energi listrik yang di gunakan pada gedung menjadi masalah dalam mengontrol (alat listrik rumah tangga) seperti lampu, kipas angin, kulkas dan televisi. Sulitnya mengontrol penggunaan listrik oleh penghuni gedung akan mempengaruhi biaya penggunaan energi yang digunakan, oleh karena itu perlunya solusi atau cara bagaimana untuk mengontrol penggunaan listrik dengan mudah.

IoT merupakan teknologi baru dalam internet akses yang dapat mengenali objek perilaku intelijen terkait dengan pengambilan suatu keputusan dan dapat berkomunikasi dengan dirinya sendiri [7]. IoT mewakili konsep secara umum dari suatu perangkat jaringan yang dapat mengumpulkan data dari seluruh dunia dan kemudian membagikan data tersebut melalui internet yang dapat diproses dan digunakan untuk berbagai tujuan. [8]. IoT dapat menghubungkan berbagai objek tidak hidup melalui koneksi internet dan dapat menghubungkan mereka untuk berbagi informasi dan dapat melakukan proses otomasi [9]. Paradigma IoT memungkinkan bahwa terdapat banyak objek yang terhubung pada jaringan internet yang mengelilingi kita secara besar besaran dan murah, dengan berbagai macam bentuk seperti objek fisik dan sistem kontrol [10]. IoT memiliki kemampuan untuk mengumpulkan dan mengirim data melalui jaringan tanpa bantuan atau intervensi manusia, IoT juga dapat mempengaruhi keputusan yang akan diambil [11]. IoT merupakan bidang multidisiplin dan infrastruktur jaringan universal yang dinamis [12]. Penelitian yang telah di publikasikan pada suatu jurnal menyatakan bahwa : IoT dapat ditemukan pada setiap aspek kehidupan sehari-hari [13].

\section{Metode Penelitian}

IoT dianggap sebagai gelombang ketiga dari World Wide Web $(W W W)$ setelah halaman web statis dan web berbasis jejaring sosial. IoT adalah jaringan di seluruh dunia yang menghubungkan berbagai jenis objek kapan saja dan di mana saja melalui protokol internet yang sangat populer bernama Internet Protocol (IP) [14]. Saat ini belum ada suatu konsensus tunggal yang disepakati bersama untuk arsitektur IoT, berbagai arsitektur banyak diusulkan oleh para peneliti yang berbeda seperti arsitekur tiga lapis dan arsitektur lima lapisan, sedangkan arsitektur IoT yang paling mendasar adalah arsitektur tiga lapis. [15]. Penelitian ini bertujuan membangun dan melakukan pengujian sebuah sistem yang dapat digunakan sebagai sarana untuk pengontrolan energi listrik sehingga pemakaian listrik dapat lebih efisien dalam penggunaannya, selain itu juga dapat mempermudah pemilik gedung dalam mengontrol biaya listrik. Lapisan persepsi (Perception Layer) dapat diartikan sebagai lapisan fisik yang memiliki perangkat sensor untuk merasakan dan mengumpulkan informasi tentang lingkungan, lapisan ini juga dapat merasakan beberapa parameter fisik atau mengidentifikasi objek pintar lainnya pada suatu lingkungan. lapisan network layer bertanggung jawab mengubungkan sesuatu hal yang cerdas ke
Perangkat jaringan dan server, termasuk fitur-fitur yang berhubungan dengan pengiriman dan pemrosesan data sensor. Lapisan aplikasi bertanggung jawab untuk mengirimkan layanan aplikasi khusus untuk pengguna, lapisan ini mendefinisikan berbagai aplikasi dimana IoT dapat digunakan, misalnya rumah pintar, kota pintar dan kesehatan pintar.[15]. keberadaan beragam handset dan nilai pasar dari layanan menjadi nilai tambah bagi industri seluler dan pengembang aplikasi, disisi lain android memiliki dampak yang mengesankan bagi konsumen [16]. Arsitektur perangkat lunak open source populer yang disediakan oleh open handset alliance diantaranya adalah android [17]. Android SDK menyediakan alat dan API yang diperlukan untuk mengembangkan aplikasi pada platform android [18]. Berdasarkan sudut pandang arsitektur, sistem operasi android dibagi menjadi empat lapisan : lapisan kernel, pustaka, dan lapisan runtime, Lapisan kerangka kerja aplikasi dan lapisan aplikasi, kernel android adalah versi modifikasi dari kernel linux2.6 yang diperbarui dari waktu ke waktu dengan berbagai versi android.[19].

Database Firebase Realtime adalah host database yang berada pada sistem cloud. Data disimpan sebagai JSON dan disinkronkan secara realtime ke setiap klien yang terhubung. Firebase realtime database memungkinkan kita untuk membuat aplikasi kolaboratif dengan menyediakan akses yang aman ke database, langsung dari kode sisi klien [20].

Mikrokontroler adalah rangkaian yang memiliki beberapa fitur penting. Unit pemrosesan pusat berkisar antara 4 bit sampai dengan 64 bit, memiliki RAM Volatile untuk menyimpan data, ROM, EPROM, EEPROM, memori flash untuk membuat pemrograman dan menyimpan parameter pemrosesan, pin I/O dua arah memungkinkan untuk mengontrol dan mendeteksi keadaan logika, UART, antarmuka komunikasi serial seperti I2C, antar muka periferal serial dan jaringan area pengontrol untuk interkoneksi sistem, periferal seperti penghitung waktu, generator PWM, pengawas waktu, penghasil jam, ADC, DAC, pemrograman sirkuit dan dukungan debuging [21].

Modul turunan pengembandan dari modul platform IoT diantaranya adalah NodeMCU ESP 8266. Fungsi yang dimiliki mirip seperti platform modul Arduino. Perbedaannya adalah pada modul ini spesial untuk "Connected to Internet". Modul NodeMCU merupakan compact board yang sangat kecil dan memiliki kemampuan untuk diprogram dan terhubung ke jaringan melalui nirkabel. Selain itu, NodeMCU memiliki pin input/output yang dapat dihubungkan ke sensor atau aktuator sehingga data dari sensor dapat dikirim ke server dan dapat mengaktifkan aktuator berdasarkan data yang diterima [22].

DHT11 adalah modul yang memiliki kompleksitas kelembaban dan suhu dengan output sinyal digital yang dikalibrasi, modul ini adalah modul gabungan untuk mengukur tingkat kelembaban dan suhu yang dapat memberikan keluaran sinyal digital yang dikalibrasi [23]. sensor DHT11 memiliki kelembaban tipe resistif, sensor ini memiliki rentang operasi daya rendah kisaran $(3 \mathrm{~V}-5 \mathrm{~V})$ 
[24]. Lapisan Jaringan disebut sebagai lapisan transmisi, lapisan ini berfungsi untuk mentransfer informasi dari perangkat sensor ke sistem pemrosesan informasi. Media transmisi dapat berupa kabel atau nirkabel dan teknologinya bisa 3G, UMTS, Wifi, Bluetooth, inframerah, ZigBee, dll., Tergantung pada perangkat sensor. Lapisan jaringan mentransfer informasi dari lapisan persepsi ke lapisan Middleware. Setiap perangkat terhubung dan berkomunikasi dengan hanya perangkat lain yang menerapkan jenis layanan yang sama. Lapisan ini bertanggung jawab untuk manajemen layanan dan memiliki tautan ke data dan menerima informasi dari lapisan jaringan dan menyimpannya dalam database [12].

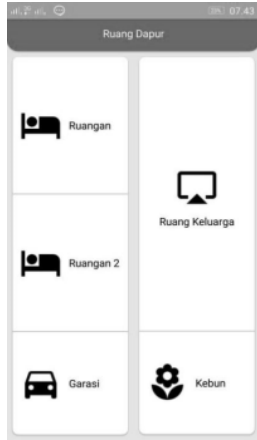

Gambar 1

Menu Kontrol Kamar

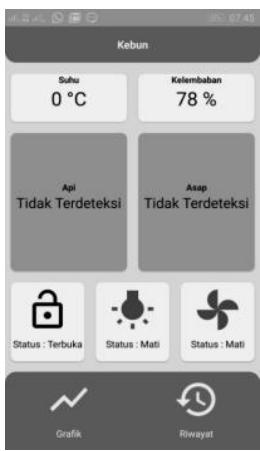

Gambar 2

Menu Kontrol Alat

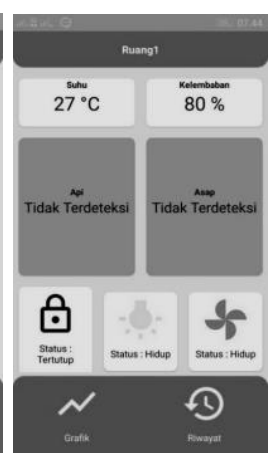

Gambar 3

Temperatur dan Kelembaban
Setelah tahap perancangan sistem dan penentuan komponen selanjutnya adalah merangkai alat sesuai dengan rancangan sistem yang telah dibuat. (2) Prototype hardware yang telah bangun berupa miniatur rumah yang terapat peralatan sederhana seperti lampu, kipas dan televisi, rangkaian yang telah dibangun akan dihubungkan dengan aplikasi agar dapat dikendalikan melalui smartphone android. (3) Jika rangkaian-rangkaian elektronik telah selesai dibangun, tahap selanjutnya adalah membangun program aplikasi menggunakan arduino IDE, kemudian aplikasi di extract kedalam bentuk apk dan di install pada perangkat android. (4) Selanjutnya prototipe dan aplikasi yang telah di install pada smartphone akan diuji coba keberhasilannya, jika hasil pengujian telah sesuai dengan rancangan, maka sistem telah berhasil. (5) Tingkat keberhasilan dapat dilihat berdasarkan akurasi yang terdapat pada android sebagai remote, apabila terjadi perubahan pada alat sesuai dengan perintah maka dapat disimpulkan bahwa uji coba berhasil. Implementasi antar muka merupakan rancangan dari sistem dilengkapi spesifikasi dari setiap gambar dan teks ada beberapa tampilan seperti menu Interface, dashboard Pengontrolan ruangan, pengelolaan user dan kontrol alat kelistrikan yang terhubung pada sistem. (1) Pada tampilan interface menu utama, aplikasi akan menampilkan icon yang berfungsi sebagai tombol berfungsi mengarahkan pengguna aplikasi untuk masuk ke sistem pengontrolan pada setiap ruangan yang ada pada gedung. (2) pada dashboard pemilihan ruangan berfungsi sebagai menu untuk memilih pilahan ruangan yang akan dikontrol alat kelistrikan dan terhubung pada sistem, (3) Menu Login berfungsi untuk pengaturan hak akses pada pengontrolan alat kelistrikan yang ada pada ruangan (Gambar 2), password hanya digunakan untuk pengelola ruangan. Menu dashboard data suhu dan kelembaban kamar (Gambar 3) adalah menu yang menampilkan temperatur suhu dan kelembaban dengan menggunakan konsep smart energy dimana suhu pada kamar ruangan yang berfungsi memberikan informasi dan menjadi indikator kipas hidup saat temperatur suhu $>30^{\prime} \mathrm{C}$ untuk lebih jelasnya dapat dilihat pada gambar 3 .

Rangkaian alat ini terdiri dari, 1 NodeMCU ESP8266, 2 buah relay yang berfungsi sebagai saklar digital yang dapat memutus dan menghubungkan alat kelistrikan rumah tangga yang terpasang pada terminal listrik di setiap kamar, lalu dua (2) inputan tegangan 5V DC, untuk lebih jelasnya bisa di lihat pada gambar 4 di bawah ini :
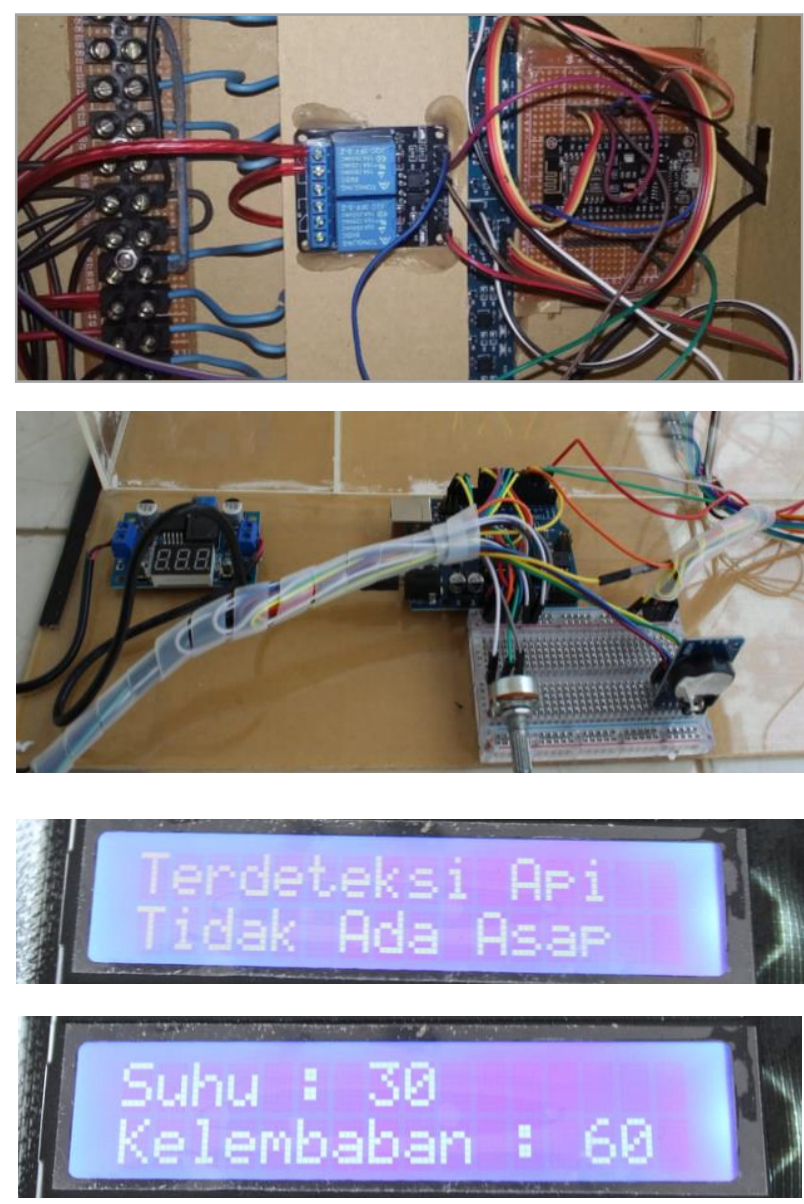

Gambar 4 Rangkaian Pengontrol Ruangan \& Display suhu dan Kelembaban

\section{Hasil Dan PeMbahasan}

Setelah menyelesaikan perangkat pengontrol peralatan berbasis IoT dan prototype smart home tahap 
berikutnya adalah melakukan pengujian sistem. Pengujian kualitas aplikasi sangat diperlukan sebelum aplikasi digunakan, tujuan dari pengujian adalah untuk meyakinkan pengguna bahwa sistem layak digunakan dan memenuhi persyaratan [26]. Untuk memastikan kualitas dalam pengembangan sistem perangkat lunak tidak hanya dibutuhkan pemantauan dan manajemen, tetapi juga kepatuhan terhadap standar yang ketat. Melalui pengukuran dan metrik, industri perangkat lunak akan memeriksa produk dan layanan yang memenuhi persyaratan [27].

ISO/IEC 9126 [28] adalah standar yang dikembangkan oleh ISO/IEC JTC1 SC7 (Subcommitte Sc7-Software and system engineering international organizaion for standarization) yang dibagi menjadi empat bagian yaitu : ISO/EIC 9126-1 - information technology - software quality characteristic and metrics - part 1: quality model, ISO/EIC 9126-2, Part 2 : external metrics, ISO/EIC 9126 - 3, Part 3 : internal metrics, ISO/EIC 9126-4, Part 4 : quality in use metrics, [29]. Pengujian kualitas aplikasi sangat diperlukan sebelum aplikasi digunakan, tujuan dari pengujian adalah untuk meyakinkan pengguna bahwa sistem layak digunakan dan memenuhi persyaratan. [26]. Pengujian ISO 9126 masuk kedalam tahap testing pada metode pengembangan Waterfall. Pengujian yang dilakukan mencakup empat aspek yaitu functionality, reliability, usability, efficiency, maintainability dan portability. Pengujian fungsionalitas adalah seperangkat atribut yang mendukung keberadaan seperangkat fungsi dan sifat-sifatnya yang ditentukan, fungsinya adalah memenuhi kebutuhan yang dinyatakan atau tersirat, ada beberapa faktor dalam pengujian fungsionalitas yaitu : suitability, accurateness, interoperability, compliance, security, suitability berarti bahwa fungsionalitas aplikasi sesuai dengan kebutuhan pengguna untuk memenuhi tugas tertentu tanpa membebani pengguna [30]. Organisasi yang membuat standardisasi / komisi elektronik internasional menetapkan ISO 9126.

Kesalahan dan ketidaksesuaian dalam penggunaan sistem diminimalisir sehingga sesuai dengan harapan pengguna. Pengujian dilakukan pada sistem dashboard smart energy menggunakan ISO 9126. Pengujian akan dilakukan dengan memberikan kuesioner kepada beberapa responden yang berfungsi sebagai pengelola gedung (admin) dan beberapa responden bertindak sebagai pengguna ruang (pengguna). Dari beberapa responden yang mengisi kuesioner akan melakukan tes yang bertujuan menguji kualitas sistem dashboard smart energy, jawaban responden untuk diproses adalah responden yang memberikan jawaban kuesioner yang valid. Skor aktual adalah jawaban seluruh responden atas kuesioner yang telah diajukan. Skor ideal adalah skor atau bobot tertinggi atau semua responden diasumsikan memilih jawaban dengan skor tertinggi. Adapun tingkat kualitas perangkat lunak di setiap aspek kualitas berdasarkan hasil jawaban kuesioner yang telah dijawab oleh para responden adalah sebagai berikut.

Aspek functionality merupakan kemampuan perangkat lunak untuk menyediakan fungsi sesuai kebutuhan pengguna, ketika digunakan dalam kondisi tertentu. Aspek fungsionalitas terdiri dari : Kesesuaian, Akurasi, Interoperabilitas dan Keamanan, mayoritas responden sangat setuju bahwa sistem dashboard smart energy memiliki fungsionalitas yang sangat baik yaitu sebesar 93\% berada dalam kriteria sangat baik.

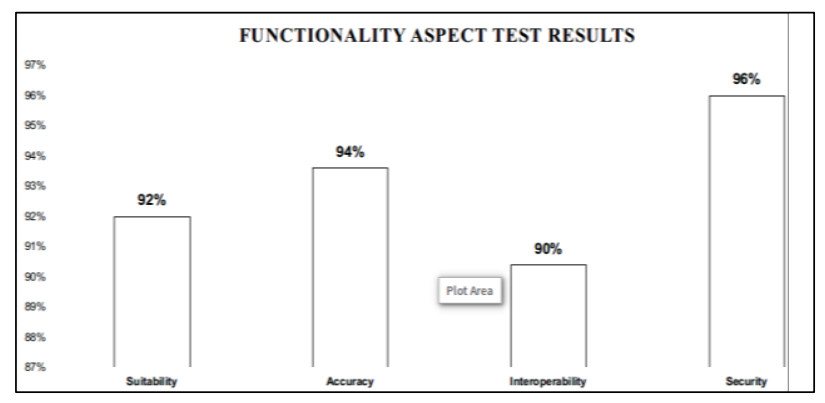

Gambar 5 Grafik hasil pengujian fungsionalitas dengan 25 Responden

Kemampuan perangkat lunak untuk mempertahankan tingkat kinerja tertentu pada saat perangkat tersebut digunakan pada suatu kondisi tertentu disebut aspek reliability. Berdasarkan analisis yang sudah dilakukan bahwa tingkat reliability pada dashboard smart energy berhasil dengan baik. Persentase keberhasilan diperoleh $77 \%$.

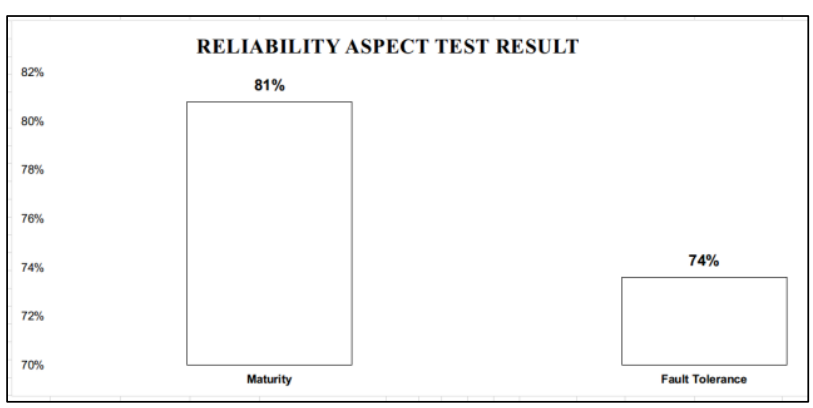

Gambar 5 Grafik Hasil Pengujian Reability dengan 25 Responden

Sedangkan kemampuan perangkat lunak untuk dipahami, dipelajari, digunakan, dan menarik bagi pengguna ketika digunakan dalam kondisi tertentu disebut dengan Aspek usability. Berdasarkan perhitungan dapat disimpulkan bahwa tingkat usability Aplikasi sistem dashboard smart energy dalam kriteria sangat baik, dengan persentase $89 \%$.

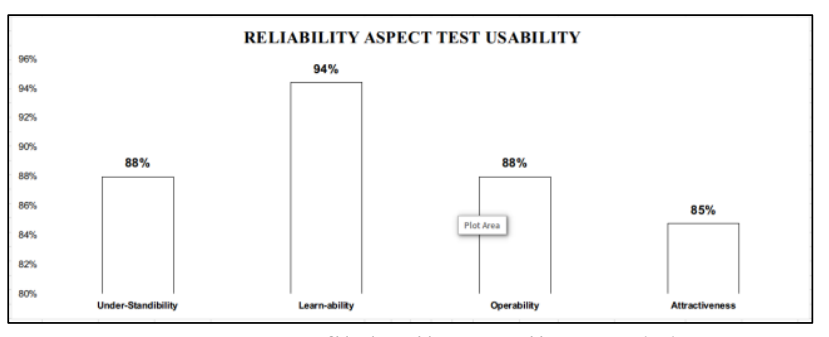

Gambar 6 Grafik hasil pengujian usability

Aspek efficiency merupakan kemampuan perangkat lunak untuk memberikan kinerja yang sesuai dan relatif 
berdasarkan jumlah sumber daya yang digunakan. Testdroid digunakan dalam pengujian aspek effeciency. Melalui aplikasi testdroid penggunaan memory (RAM) dan CPU dapat diamati sehingga dalam pengujian aspek effeciency ini di gunakan device yang sudah disediakan oleh testdroid yang menggunakan device LG Google Nexus 5 D280 5.0, berikut ini hasil pengujian aspek effeciency dengan tools testdroid (Gambar 7, 8, 9).

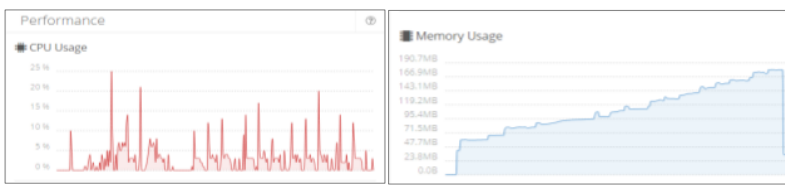

Gambar 7 Pengujian Efficiency Tahap 1

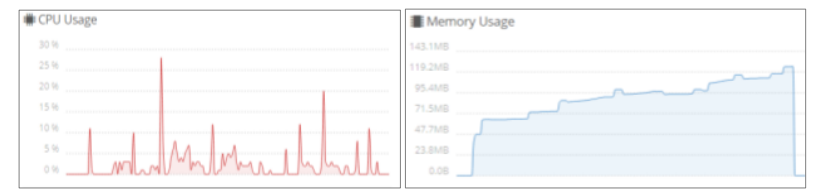

Gambar 8 Pengujian Efficiency Tahap 2

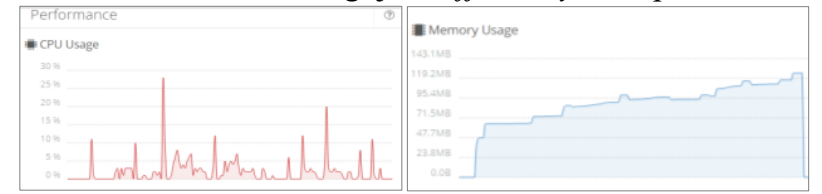

Gambar 9 Pengujian Efficiency Tahap 3

Hasil pengujian aspek efficiency tahap pertama pada dashboard smart energy memperoleh tingkat efesiensi CPU tertinggi pada level 25\% dan turun secara stabil pada persentasi 10\%, untuk memori sebesar lebih dari 166,9MB diawali dengan penggunaan memori sebesar 47.7MB dari total alokasi 190.7MB. Selanjutnya pada Pengujian aspek efficiency tahap kedua pada dashboard smart energy memperoleh tingkat efesiensi CPU tertinggi pada level $28 \%$ dan turun secara stabil pada persentasi $10 \%$, untuk penggunaan memori tertinggi sebesar $119,2 \mathrm{MB}$ diawali dengan penggunaan memori sebesar $47.7 \mathrm{MB}$ dari total alokasi 143.1MB. pada pengujian aspek efficiency tahap ketiga pada dashboard smart energy memperoleh tingkat efesiensi CPU tertinggi pada level 28\% dan turun secara stabil pada persentasi $10 \%$, untuk penggunaan memori tertinggi sebesar $119,2 \mathrm{MB}$ diawali dengan penggunaan memori sebesar $47.7 \mathrm{MB}$ dari total alokasi $143.1 \mathrm{MB}$, pengujian tahap ketiga memperoleh nilai yang sama dengan pengujian tahap kedua.

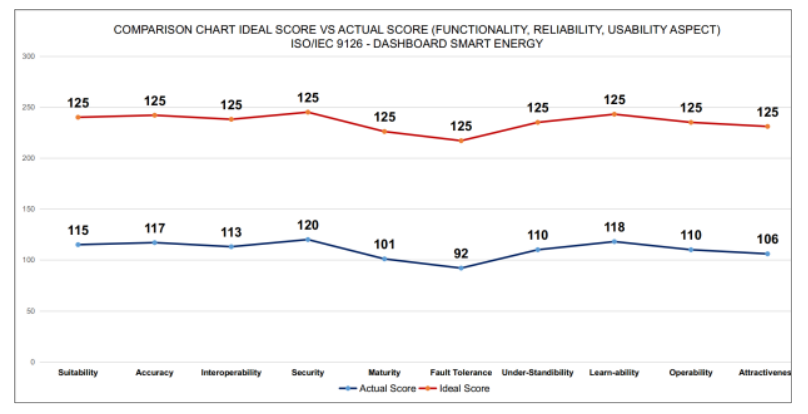

\section{Gambar 10 Nilai Actual \& Ideal Score}

Adapun presentase pencapaian nilai actual score dari seluruh aspek pengujian memperoleh 93\% pada aspek Functionality yang terdiri dari beberapa kriteria (Suitability 92\%, Accuracy 94\%, Interoperability 90\%, Security $96 \%$ ). pada aspek Reliability memperoleh nilai persentase pengujian sebesar $77 \%$ dengan beberapa kriteria didalamnya yaitu: (maturity $81 \%$, fault tolerance $74 \%$ ). pada aspek usability memperolah nilai persentase pengujian sebesar $89 \%$ dengan beberapa kriteria didalamnya yaitu : (understandibility $88 \%$, learnability $94 \%$, operability $88 \%$, attractivness $85 \%$ ).

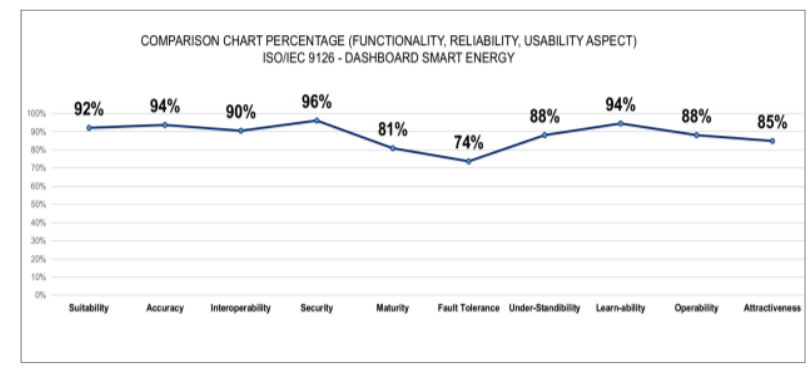

Gambar 11 Nilai Persentase (Actual Score)

\section{KESIMPULAN}

Berdasarkan hasil pengujian sistem dashboard smart energy menggunakan ISO/IEC 9126, diperoleh hasil pada aspek functionality $93 \%$, reliability $77 \%$ dan usability $89 \%$. dengan hasil yang diperoleh maka dapat disimpulkan bahwa pengujian kualitas aplikasi pada sistem dashboard smart energy layak digunakan dan memenuhi persyaratan.

\section{UCAPAN TERIMAKASIH}

Terima kasih kepada Direktorat Pendidikan Tinggi (DIKTI) yang telah memberikan dukungan sehingga penelitian ini dapat terlaksana.

\section{Daftar Pustaka}

[1] Ahmad Wahid, "Analisis Kapasitas Dan Kebutuhan Daya Listrik Untuk Menghemat Penggunaan Energi Listrik Di Fakultas Teknik Universitas Tanjungpura," $J$. Tek. Elektro UNTAN, vol. 2, no. 1, 2014.

[2] K. Maslichah, "Hemat Energi Listrik: Studi Kasus Di Badan Diklat Provinsi Banten," J. Lingk. Widyaiswara, vol. 3, no. 1, pp. 47-52, 2016, [Online]. Available: http:/juliwi.com/published/E0301/Juliwi0301_4752.pdf.

[3] I. G. P. M. Eka Putra, I. A. D. Giriantari, and L. Jasa, "Monitoring Penggunaan Daya listrik Sebagai Implementasi Internet of Things Berbasis Wireless Sensor Network," Maj. Ilm. Teknol. Elektro, vol. 16, no. 3, p. 50, 2017, doi: 10.24843/mite.2017.v16i03p09.

[4] A. González-Vidal, V. Moreno-Cano, F. Terroso-Sáenz, and A. F. Skarmeta, "Towards Energy Efficiency Smart Buildings Models Based on Intelligent Data Analytics," Procedia Comput. Sci., vol. 83, no. BigD2M, pp. 994- 
999, 2016, doi: 10.1016/j.procs.2016.04.213

[5] D. Sciuto and A. A. Nacci, "On How to Design Smart Energy-Efficient Buildings," Proc. - 2014 Int. Conf. Embed. Ubiquitous Comput. EUC 2014, no. April, pp. 205-208, 2014, doi: 10.1109/EUC.2014.37.

[6] B. Banerjee, A. Seetharam, A. Mukherjee, and M. Kanti Naskar, "Characteristic time routing in information centric networks," Comput. Networks, vol. 113, pp. 148-158, 2017, doi: https://doi.org/10.1016/j.comnet.2016.12.009.

[7] Z. Kamal, A. Mohammed, E. Sayed, and A. Ahmed, "Internet of things applications, challenges and related future technologies," World Sci. News, vol. 67, no. 2, pp. 126-148, 2017, [Online]. Available: www.worldscientificnews.com.

[8] V. Sharma and R. Tiwari, "A review paper on 'IOT' \&amp; It"s Smart Applications," Int. J. Sci. Eng. Technol. Res., vol. 5, no. 2, pp. 472-476, 2016, [Online]. Available: http://ijsetr.org/wpcontent/uploads/2016/02/IJSETR-VOL-5-ISSUE-2472-476.pdf.

[9] F. Jindal, R. Jamar, and P. Churi, "Future and Challenges of Internet of Things," Int. J. Comput. Sci. Inf. Technol., vol. 10, no. 2, pp. 13-25, 2018, doi: 10.5121/ijcsit.2018.10202.

[10] A. Strielkina, V. Kharchenko, and D. Uzun, "A markov model of healthcare internet of things system considering failures of components," CEUR Workshop Proc., vol. 2104, pp. 530-543, 2018.

[11] R. Khan, S. U. Khan, R. Zaheer, and S. Khan, "Future internet: The internet of things architecture, possible applications and key challenges," Proc. - 10th Int. Conf. Front. Inf. Technol. FIT 2012, no. December, pp. 257 260, 2012, doi: 10.1109/FIT.2012.53.

[12] D. Jain, P. V. Krishna, and V. Saritha, "A Study on Internet of Things based Applications," pp. 886-888, 2012, [Online]. Available: http://arxiv.org/abs/1206.3891.

[13] S. P. S. Brighty, P. Selvanayaki, and M. Kiruthika, "Survey on Challenges and Applications of Internet-ofThings," vol. 6, no. 11, pp. 1294-1302, 2015.

[14] M. Bilal, "A Review of Internet of Things Architecture, Technologies and Analysis Smartphone-based Attacks Against 3D printers.," CoRR, vol. abs/1708.0. 2017, [Online]. Available: http://arxiv.org/abs/1708.04560.

[15] P. Sethi and S. R. Sarangi, "Internet of Things: Architectures, Protocols, and Applications," J. Electr. Comput. Eng., vol. 2017, p. 9324035, 2017, doi: $10.1155 / 2017 / 9324035 . t$

[16] V. Anand, "a R Obust C Lient a Rchitecture on a Ndroid T O C Ater E Nd -2-E Nd R Eal - Time C Ontent M Anagement and P Ersonalized Iptv," Int. J., vol. 2, no. 3, pp. 67-78, 2010.

[17] H. Pieterse, M. S. Olivier, and R. P. Van Heerden, "Reference architecture for android applications to support the detection of manipulated evidence," SAIEE Africa Res. J., vol. 107, no. 2, pp. 92-103, 2016, doi: 10.23919/saiee.2016.8531545.

[18] S. Holla and M. M. Katti, "Android Based Mobile
Application Development And Its Security," Continuum (N. Y)., vol. 3, no. 3, pp. 486-490, 2012, doi: 10.1080/10304312.2012.706462.

[19] J. Khan and S. Shahzad, "Android Architecture and Related Security Risks," Asian J. Technol. Manag. Res., vol. 05, no. March, pp. 2249-892, 2016.

[20] A. M. A. P. P. Analytics, "Introducing Firebase Analytics."

[21] M. K. Parai, B. Das, and G. Das, "An Overview of Microcontroller Unit: From Proper Selection to Specific Application," no. 6, pp. 228-231, 2013.

[22] E. Media and M. Rif, "Internet of Things ( IoT ): BLYNK Framework for Smart Home," vol. 2019, pp. 579-586, 2019, doi: 10.18502/kss.v3i12.4128.

[23] A. Srivastava, A. Prakash, and R. Tripathi, "Location based routing protocols in VANET: Issues and existing solutions," Veh. Commun., vol. 23, p. 100231, 2020, doi: https://doi.org/10.1016/j.vehcom.2020.100231.

[24] J. P. Sipani, R. H. Patel, T. Upadhyaya, and V. T. Patel, "Temperature \& Humidity Monitoring \& Control System Based on Arduino and Sim900a Gsm Shield," Int. J. Electr. Electron. Data Commun., vol. 5, no. 11, pp. 2320-2084, 2017, [Online]. Available: http://www.iraj.in/journal/journal_file/journal_pdf/1423-151703294362-68.pdf.

[25] T. C. de Sousa, L. Kelvin, C. Dias Neto, and C. Giovanni N. de Carvalho, "A Formal Semantics for Use Case Diagram Via Event-B," J. Softw., vol. 12, no. 4, pp. 189-200, 2017, doi: 10.17706/jsw.12.3.189-200.

[26] T. Abdelaziz, M. Elammari, and W. Bani, "Applying the ISO Standard in Assessing the Quality of Software Systems," Adv. Comput. Sci. Inf. Technol., vol. 2, no. 3, pp. 28-32, 2015.

[27] J. F. Andry, J. S. Suroso, and D. Y. Bernanda, "Improving quality of smes information system solution with ISO 9126," J. Theor. Appl. Inf. Technol., vol. 96, no. 14, pp. 4610-4620, 2018.

[28] P. Botella et al., "ISO/IEC 9126 in practice: what do we need to know?," Softw. Meas. Eur. Forum 2004, pp. 297-306, 2004, [Online]. Available: http://www.lsi.upc.es/ jmarco/publications_pdfs/SME F2004.pdf.

[29] G. Wang, D. Y. Bernanda, J. F. Andry, A. Nurul Fajar, and Sfenrianto, "Application Development and Testing Based on ISO 9126 Framework," J. Phys. Conf. Ser., vol. 1235, no. 1, 2019, doi: 10.1088/17426596/1235/1/012011.

[30] B. Behkamal, M. Kahani, and M. K. Akbari, "Customizing ISO 9126 quality model for evaluation of B2B applications," Inf. Softw. Technol., vol. 51, no. 3, pp. 599-609, 2009, doi: 10.1016/j.infsof.2008.08.001. 